\title{
ERCP and laparoscopic cholecystectomy in a combined (one-step) procedure with a novel technique
}

\author{
Luigi De Santis
}

From 26th National Congress of the Italian Society of Geriatric Surgery

Naples, Italy. 19-22 June 2013

\section{Background}

This study compared the benefit of the novel one- step procedure for the managment of calculous biliary disease.

\section{Methods}

A retrospective review of 25 geriatric patients was conducted one-step procedure with positionament of loop in jejunum for reductions a little bowel distenction. In 24 of the patients, the one-step technique was successful (96\%); in the remaining 1 patient (4\%), conversion open technique was necessary; in this case not positionament of loop in jejunum. We define the one-step procedure to be a laparoscopic cholecystectomy whit IOC to confirm the presence of stone, to be a gold standard; intraoperative ERCP whit stone extraction was conected if necessary as part of the one-step procedure.

\section{Result}

This technique evidence a statistically significant difference of the hospital cost, such us the length of the stay and pre operative day and reduce the high conversion rate with alternatively technique in two-step. The incidence of overall complications was lower in the one-step technique. The findings showed that one-step technique was associated with less clinical pancreatitis respect at the twostage technique.

\section{Conclusion}

A laparoscopic cholecystectomy after ES is lengthier and more difficult then in uncomplicated cholelithiasis and should therefore be performed by an experienced surgeon.
This new technique appears to be a significant conversion reduction versus two step procedure, and reduce the cost of hospitality and length of stay and preoperative days. Further research with a larger study population is necessary to determine the additional benefits of this procedure.

Published: 16 September 2013

\section{References}

1. Noel R, Enochsson L, Swahn F, Löhr M, Nilsson M, Permert J, Arnelo U: A 10-year study of rendezvous intraoperative endoscopic retrograde cholangiography during cholecystectomy and the risk of post-ERCP pancreatitis. Surg Endosc 2013.

2. Reinders JS, Gouma DJ, Heisterkamp J, Tromp E, van Ramshorst B, Boerma D: Laparoscopic cholecystectomy is more difficult after a previous endoscopic retrograde cholangiography. HPB (Oxford) 2013, 15(3):230-4.

3. Wang B, Guo Z, Liu Z, Wang Y, Si Y, Zhu Y, Jin M: Preoperative versus intraoperative endoscopic sphincterotomy in patients with gallbladder and suspected common bile duct stones: system review and metaanalysis. Surg Endosc 2013.

4. Jones M, Johnson M, Samourjian E, Slauch K, Ozobia N: ERCP and laparoscopic cholecystectomy in a combined (one-step) procedure: a random comparison to the standard (two-step) procedure. Surg Endosc 2012.

5. Pereira-Graterol F, Venales-Barrios Y, Bousquet-Suárez J, Cáceres-Cauro A, Romero-Bravo C, Moreno-Rodríguez J, Rodríguez-Perero L: [The "rendezvous" maneuver as a technical option to access the bile ducts: Case series report]. Rev Gastroenterol Mex 2012, 77(4):224-8.

6. Arezzo A, Vettoretto N, Famiglietti F, Moja L, Morino M: Laparoendoscopic rendezvous reduces perioperative morbidity and risk of pancreatitis. Surg Endosc 2013, 27(4):1055-60, doi: 10.1007/s00464-012-2562-3.

doi:10.1186/1471-2482-13-S1-A15

Cite this article as: De Santis: ERCP and laparoscopic cholecystectomy in a combined (one-step) procedure with a novel technique. BMC Surgery 2013 13(Suppl 1):A15. 